\title{
Update - Noise Induced Hearing Loss and the Military Environment
}

\author{
Maj PA Cain \\ MB, ChB, MMedSc, DAvMed, MFOM, RAMC \\ Specialist in Aviation Medicine \\ Aviation Branch, Airfield Camp, Netheravon Wilts SP4 9SF
}

SUMMARY: Although Noise Induced Hearing Loss (NIHL) is well recognised there are an increasing number of associations that are important in its study and to a lesser extent in clinical practice. For many there is controversy over whether there is a causal relationship or a confounding effect but of these presbyacusis is the most important. The PULHHEEMS assessment $\mathrm{H3}$ is currently the first level of abnormal hearing. Between $\mathrm{H} 2$ and $\mathrm{H3}$ there is a performance decrement and compensation is awarded at levels of NIHL less than H3. If the measurement of NIHL is to be used as a tool in the Army Hearing Conservation Program (AHCP) then the emphasis must be placed on the change from $\mathrm{H} 1$ to $\mathrm{H} 2$ and not from $\mathrm{H} 2$ to $\mathrm{H3}$.

\section{Introduction}

NIHL may appear a spent subject but without a sound understanding of all its associations it is difficult to focus on the more meaningful issue of hearing conservation. In the Army NIHL is chiefly seen as being related to exposure to weapon noise and research tends to be in that context $(1,2)$. There are however other sources of exposure in both military and civilian environments that potentially affect hearing loss and confound the study of NIHL. These may either cause hearing loss in their own right or modify the way the human auditory system reacts to noise. The last 1015 years have seen advances in the study of NIHL and a degree of change in the perception of what constitutes significant loss. The AHCP has however remained essentially unchanged since its inception. This paper explores current issues in NIHL with particular regard for the practice and study of hearing conservation in the military.

\section{Historical Perspective}

In the nineteenth century Fosbroke noted that deafness in the military was caused by the explosions of cannons ( 3 ) and by the turn of the century standard Ear, Nose and Throat texts listed occupations that exposed workers to excessive noise and led to deafness; these included artillerymen, riflemen and sailors.

The First World War saw the first use of magazine and belt fed weapons using metal cartridges filled with smokeless-powder which greatly increased the energy and noise of the gases exiting the muzzle. Additionally high explosive replaced black-powder and there was a dramatic increase in the numbers with hearing damage (4). In the French Army the war-time prevalence of pensionable ear disabilities was $10-20 \%$ (5), the reporting author implying that almost all were due to NIHL. In England, however, the Oxford War Primers dismissed hearing loss as malingering and exaggeration and after the war Major $\mathrm{T}$ Jefferson Faulder RAMC reported hearing deficit from gunfire to be temporary.

In the Second World War there was a revival in military interest in NIHL as the operational consequences were recognised; Daggett stated "men with a high pitched loss were undoubtedly handicapped in night operations when the snap of a twig might be of significance". Although by the end of the war all three Services were making some effort to protect hearing and it was not until 1974 that the AHCP was introduced against the background of the Health and Safety at Work Act of 1974.

\section{Noise Induced Hearing Loss}

The American Occupational Medicine Association Noise and Hearing Conservation Committee succinctly defined NIHL loss as a sensorineural loss, usually bilateral but rarely producing a profound deafness. The frequencies mos commonly affected are $3-6 \mathrm{kHz}$ with the greatest loss usually at $4 \mathrm{kHz}$; maximal levels of loss are reached in five to ten years (6). Unless there is a history of work related exposure this should not be labelled as occupationals Exposure to noise above $90 \mathrm{~dB}_{\mathrm{A}} \mathrm{L}_{\text {ep.d }}$ causes damage in the unprotected ear and levels below 75-80 $\mathrm{dB}_{\mathrm{A}} \mathrm{L}_{\mathrm{ep}, \mathrm{d}}$ do not $\vec{F}^{+}$ cause damage $(7,8)$. Between these levels there is debate over the size and cause (confounded by non-occupational exposure) (9) of the effect and although both UK and USA legislation are based on the upper limit they are said to protect only $85 \%$ of exposed workers (10).

Low level noise causes changes in the organelles and nuclei of the hair cells and an increase in the lysosome numbers leading to membrane damage, impaired regulation of ionic contents and ultimately cell loss. The mechanism of damage at higher levels of exposure $\left(140-150 \mathrm{~dB}_{\mathrm{A}}\right)$ is mechanical. Shearing forces cause damage to the stereocillia of the hair cells leading to a loss of function. Damage also occurs at the synapses with the eighth cranial nerve. Other investigators have identified microvascular changes during noise exposure that induce ischaemia which may result in reduced auditory sensitivity (11). Although thought to be irreversible recent research has demonstrated regeneration of the sensory cells is possible at least in some animals (12).

\section{Personal Factors}

The most important confounding factor in the study of NIHL is presbyacusis. In contrast to NIHL the histopathological changes seen include degeneration of the stria vascularis and a loss of spiral ganglion cells and only

\section{.}


limited loss of hair cells. Presbyacusis has a similar pattern on audiometry to NIHL, although the characteristic $4 \mathrm{kHz}$ notch is not seen, in practice however this is not useful for distinguishing the two conditions as the notch may not be present in NIHL (13).

The fact that hearing diminishes with age or exposure to noise is well recognised, the relationship between the two is however much less clear. There are two distinct areas, the interaction between age related and noise related damage and the susceptibility of the ageing ear to NIHL. The different sites of damage mitigate against a simple additive interaction between noise and ageing. Rather the permanent damage caused to different structures, by both factors individually, leads to a cumulative interaction that does not reach the sum of the damage at the two sites (14). Finally there appears to be no clear association between previous hearing loss and future susceptibility to hearing loss, arguably those that have been affected are most sensitive to loss, but a simple alternative explanation is "the less there is to lose, the less will be lost" $(15,16)$.

There is strong evidence that smokers have worse hearing than non-smokers (17). However different workers have interpreted this as smoking leading to an increased susceptibility to NIHL (18) or as a non-causal association with perhaps smoking itself causing the hearing loss (15).

Attempts to tie race and eye colour with melanin levels and NIHL have met with limited success. Blue eyes (relative lack of melanin) are weakly linked with NIHL (19) whereas black skin appears to have a protective effect. There is less hearing loss in a black population than white but before this difference is attributed to the occupational noise further research is required into differential ageing effects and socio-economic behaviour (20).

Gender has been linked to hearing levels and authors using ISO 1999 and ISO 7029 have necessarily assumed females to have less age related loss than males. This has been confirmed in a large longitudinal study in the USA (21) but there is controversy about how the sexes respond to noise. In the presence of noise males appear to fare worse than females but more rigorous analysis of the exposure history is required before this can be attributed to biological susceptibility.

Other factors that have been associated with NIHL include a raised cholesterol level, diabetes, high blood pressure and cardiovascular risk factors $(22,23)$. A common thread running through these associations, including smoking, is cochlea blood supply, but research has so far failed to prove a conclusive link. In general with the exception of age these factors tend to be small when compared to the effects of noise but despite all the research there still appears to be considerable individual variation in the susceptibility of NIHL. Areas for future research include the protective effects of the acoustic reflex, toughening of the auditory system by exposure to noise and the role of the efferent auditory nervous system in mediating cochlea function (24).

\section{External Factors}

Ototoxic drugs can act synergistically with noise to produce hearing loss. However this has only been shown for 3 aminoglycosides and cisplatin where a common mechanism $\stackrel{\mathbb{\complement}}{\complement}$ of action exists. The evidence for the threshold shift seen 0 with salicylate use interacting with that produced by noise is inconclusive and most likely does not exist (25).

Unlike noise, chemical agents may cause damage to any $\overrightarrow{\vec{F}}$ part of the auditory system. Some common neurotoxic agents such as lead, mercury, toluene, styrenetrichloroethylene, xylene and n-hexane are also ototoxic yet $\overline{\bar{m}}$. their interaction with noise is unclear but seems to be related $\overrightarrow{\mathbb{D}}$ to the site and mechanism of action (26). Of this group organic solvents have caused the most interest recently withes toluene and styrene having been shown to cause damage to $\overrightarrow{0}$ the hair cells (27). There may be a direct interaction with noise as in the case of toluene (28) but even if one does not $\vec{\circ}$. exist for other solvents they clearly constitute a confounding factor in the study of hearing conservation.

Possible physical associations with NIHL include? vibration, especially vibration white finger and the $\vec{P}$ protective effect of a reduced body temperature (29). Exercise has been shown to increase hearing loss, possible r as a result of increased core temperature. This may simplyo be due to the reduced efficiency of hearing protection thato moves during physical activity thus breaking the seal $(30 \Phi)$

\section{Noise Exposure}

Sources of noise exposure in the Army may be divide into continuous noise, similar to that found in industry, aim impulse noise. Workshop and maintenance areas may hole intense noise sources such as main battle tank engins which, when run up for servicing, produce $125 \mathrm{~d}$. Helicopter crews and passengers are exposed to cockpito noise of $102 \mathrm{~dB}_{\mathrm{A}}$ (Gazelle) whilst grounderew whoo approach the aircraft are exposed to considerably more. $\mathbb{D}$ Armoured fighting vehicles are a potent source of noise with $\overrightarrow{\vec{\sigma}}$ their enclosed crew compartment having internal noise 3 levels of $115 \mathrm{~dB}_{\mathrm{A}}$.

The most conspicuous cause of exposure to impulse noise in the military environment is small arms fire giving as higher peak level, shorter duration and lower repetition rate than industrial noise. Mechanical damage to the hair cells progresses quicker than metabolic damage and Table 1

\section{Table 1}

Typical military weapon noise $(\mathbf{3 1 , 3 2})$

\begin{tabular}{|c|c|}
\hline Weapon & $\begin{array}{c}\text { Peak } \\
\text { Pressure }(\mathrm{dB})\end{array}$ \\
\hline Thunderflash & 200 \\
\hline 84mm Anti-armour weapon & 188 \\
\hline Medium mortar & 188 \\
\hline Medium artillery & 180 \\
\hline Service rifle at firer's ear & 160 \\
\hline Tank gun inside closed down tank & 154 \\
\hline Multiple launch rocket system crew position & 145 \\
\hline
\end{tabular}


reveals that most weaponry is in the category that causes this type of damage $(31,32)$. Both industrial and weapon impulse noise are thought to produce greater hearing loss than continuous noise (33).

There is a clear association between shooting and hearing loss based on the asymmetry of the loss with right handed firers having greatest loss in the ear closest to the muzzle, the left (34). Even after matching for age, occupational exposure, salicylate consumption, blood pressure, cholesterol, smoking and vibration-induced white finger the effect still exists (35).

\section{Impairment and Disability}

Impairment of hearing is an abnormality of function of the auditory system usually assessed objectively by audiometry. Disability implies a state worse than impairment and in particular a difficulty in perceiving speech. The speech frequencies are $0.5-4 \mathrm{kHz}$ with $1.5 \mathrm{kHz}$ being the dividing line between the transmission of vowels and consonants. Difficulty in discriminating consonants is an early problem but it is only in more advanced disease that true disability occurs. Speech discrimination in noisy environments causes the most problems (33) and NIHL has been associated with poor word recognition due to a reduced ability to temporally resolve auditory information between gaps in the environmental noise (36). Other research has indicated the presence of a secondary distortion in the hearing impaired ear which makes speech perception worse than that implied by audiometry alone (37). Mission success in the armoured battle has been directly linked to speech intelligibility (38).

In the American Army a striking difference in performance was found between soldiers with normal hearing level that fell between the British Army PULHHEEMS grade $\mathrm{H} 2$ and $\mathrm{H} 3$ thresholds (39). The distances at which two military sounds can be heard is summarised in Table 2 .

Table 2

Distance at which sounds are heard with normal and impaired hearing

\begin{tabular}{lcc}
\hline Sound & Normal Hearing & $\begin{array}{c}\text { Impaired Hearing } \\
\text { (H2-H3) }\end{array}$ \\
\hline $\begin{array}{l}\text { Rifle bolt operating } \\
\text { Approaching footsteps }\end{array}$ & $1000 \mathrm{~m}$ & $210 \mathrm{~m}$ \\
\hline $\begin{array}{l}\text { Footsteps and temporary } \\
\text { threshold shift }\end{array}$ & $100 \mathrm{~m}$ & $5.5 \mathrm{~m}$ \\
\hline
\end{tabular}

\section{Statutory And Occupational Compensation}

Although compensation is not paid by the Army it is useful to examine the levels at which other organisations award payment as a guide to the point beyond which meaningful loss exists. NIHL compensation schemes tend to be based around the frequencies of 1,2 and $3 \mathrm{kHz}$, with some including adjacent frequencies. Table 3 gives the basic details of five schemes in use and one proposal for a replacement UK scheme. The average loss represents the
Table 3

Frequencies and entry thresholds in hearing compensation schemes compared to those in the AHCP

\begin{tabular}{|c|c|c|c|}
\hline Organisation & $\begin{array}{l}\text { Frequencies } \\
\text { Used }(\mathrm{kHz})\end{array}$ & $\begin{array}{l}\text { Average } \\
\text { loss (dB) }\end{array}$ & Notes \\
\hline$\overline{\mathrm{UK}}$ & $1,2,3$ & 50 & Represents $20 \%$ disability \\
\hline $\begin{array}{l}\text { Inter-Society Working } \\
\text { Group on Hearing } \\
\text { Disability (41) }\end{array}$ & $1,2,3$ & -10 & $\begin{array}{l}38 \% \text { disability at current } \\
\text { UK entry level } 50 \mathrm{~dB} \\
\text { average. (UK proposed) }\end{array}$ \\
\hline $\begin{array}{l}\text { American Medical } \\
\text { Association (State) }\end{array}$ & $0.5,1,2,3$ & at least $\overline{25}$ & $100 \%$ disability at $92 \mathrm{~dB}$ \\
\hline$\overline{\mathrm{NIOSH}}$ (Federal) & $1,2,3$ & at least 25 & $100 \%$ disability at $\overline{92 \mathrm{~dB}}$ \\
\hline$\overline{\text { Australia }}$ & $\begin{array}{c}0.5,1,1.5 \\
2,3,4\end{array}$ & approx 20 & $\begin{array}{l}\text { Weighted average used for } \\
\text { calculation of disability }\end{array}$ \\
\hline$\overline{\text { Canada }}$ & $0.5,1,2,3$ & 35 & $100 \%$ disability at $96.6 \mathrm{~dB}$ \\
\hline \multirow[t]{2}{*}{$\overline{\text { British Army (H3) }}$} & $0.5, \overline{1,2}$ & approx 28 & Scheme uses summation \\
\hline & $3,4,6$ & approx 41 & not averages \\
\hline
\end{tabular}

point at which compensation is first paid and is commonly described as the "low fence".

Comparison with the AHCP reveals the lower limit for entry to the first band considered abnormal (H3) is less conservative than that of most schemes excepting the Industrial Injuries Compensation Scheme in the UK. A simple comparison can mislead as the frequencies used are different and in the Army hearing loss needs only to exceed either the low or high frequency limit. A soldier could therefore have NIHL making them $\mathrm{H} 3$ and yet still haveo relatively intact speech frequencies. Even so the AHCPO appears only to take account of hearing loss when it reaches levels that others would compensate and it cannot therefore function effectively. Arguably the system is intended as one documenting fitness for work and not compensation however communication needs must be represented when assessing fitness for work as well as compensation.

When the high frequencies are predominantly affected little day to day difficulty should occur. Even so in 1989 a court awarded compensation of between $£ 2200$ and $£ 12500$ for modest NIHL to 23 Ford Motor Company workers. Of these 10 equated to the $\mathrm{H} 2$ category with one "not troubled by hearing loss every day".

Trade Unions have negotiated no fault compensation deals with insurance companies and management that bypass statutory schemes. These rely only on documented exposure to $90 \mathrm{dBA}$ for one year and payment begins at levels as low as an average loss of $10 \mathrm{~dB}$, inside even the limit for $\mathrm{H} 2$ (40).

\section{Conclusion}

Noise as a cause of hearing loss has been recognised for at least two centuries but as research progresses an increasingly complex picture emerges (41). Although exposure levels exist they do not guarantee protection against either continuous or impulse noise. Race, eye colour, smoking and gender have been associated with NIHL but 
not causally. Industrial chemicals, vibration and temperature may all play a part in mediating damage but perhaps the most rewarding lines for future research are those which link hearing loss with cochlea blood flow and the auditory system's own protective responses. Despite all these presbyacusis remains the main confounding factor, although the exact relationship has yet to be elucidated.

The value of good hearing to a soldier is apparent and yet investigation has shown a performance decrement even before the currently accepted limit for abnormality, H3, is reached. Compensation schemes, notably in the USA, make payments at levels similar to the threshold for entering the H3 bracket and UK civil courts at the H2 level. No fault schemes have taken this further and pay at levels around the $\mathrm{H} 1-\mathrm{H} 2$ border.

It is patently wrong that the action level in the AHCP should be set at a similar point to that which others use for compensation. In its current form the AHCP documents established hearing loss rather than providing a basis for monitoring and acting on early loss. It is felt, therefore, that greater emphasis should be placed on the change in hearing from $\mathrm{H} 1$ to $\mathrm{H} 2$ rather than from $\mathrm{H} 2$ to $\mathrm{H} 3$.

\section{REFERENCES}

1. ANDERSON J. An Audiometric Survey of Royal Artillery Gun Crews Following Operation Corporate. JR Army Med Corps 1984; 130: 100-8.

2. RICHARDSON JC. The Effects of the Gulf War on Hearing Acuity of Tank Crews. APRE Report 94R038 Farnborough: Hants. Army Personnel Research Establishment, MOD.

3. Pelmear P. Noise and Vibration. In: McDonald JC, ed. Epidemiology of Work Related Diseases. London: BMJ Publishing Group, 1995; 185-205.

4. Editorial. The Deaf Soldier. J Laryngol Otol 1917; XXXII (11): 337-8.

5. BRYANT WS. Prevalence of Ear Injuries and Diseases in the French Army. J Laryngol Otol 1917; XXXII (11): $338-40$.

6. American Occupational Medicine Association Noise and Hearing Conservation Committee. Committee Report. Occupational Noise Induced Hearing Loss. $J$ Occup Med 1989; 31(12): 996.

7. BURNS W, Robinson DW. Hearing and Noise in Industry. London: HMSO, 1970.

8. National Institutes of Health. Consensus Development Conference on Noise and Hearing Loss at the National Institute of Deafness and Other Communication Disorders. Bethesda: NIH, 1990.

9. Ishil E, Talbott E. Why is There Noise Induced Hearing Loss in Individuals Exposed to Occupational Noise Levels Below Occupational Safety and Health Act Threshold? Am J Epidemiol 1994; 139(11): S66.

10. Health and Safety Commission. Prevention of Damage to Hearing from Noise at Work: Draft Proposals for Regulations and Guidance. London: HMSO, 1987.

11. QUIRK WS, SEIDMAN MD. Cochlea Vascular Changes in Response to Loud Noise. Am J Otol 1995; 16(3):
$322-5$.

12. Henderson D, Hamernik RP. Biological Bases of Noise Induced Hearing Loss. In: Morata TC, Dunn $\frac{3}{\mathbb{\alpha}}$ DE, eds. Occupational Medicine: State of the Art $\stackrel{\varnothing}{\circledR}$ Reviews - Occupational Hearing Loss. Philadelphia: $\delta$ Hanley and Belfus, 1995.

13. Rosenhall U, Pedersen KE. Presbyacusis and? Occupational Hearing Loss. In: MORATA TC, DUNN $\overrightarrow{\vec{F}}$ DE, eds. Occupational Medicine: State of the Art $\overrightarrow{0}$ Reviews - Occupational Hearing Loss. Philadelphia: Hanley and Belfus, 1995; 593-607.

14. BoEtTCHER FA, Gratton MA, SChMiedt RA. Effects of Noise and Age on the Auditory System. Occup Med 1995; 10(3): 577-91.

15. WARD WD. Endogenous factors related to $\vec{\circ}$ susceptibility to damage from noise. Occup Med 1995; 10(3): 561-75.

16. GRAYSON JK. Previous Hearing Loss and Susceptibility to Future Permanent Threshold Shifts. Milit Med 1992; 157(5): 248-9.

17. Chung DY, Wilson GN, Gannon P, Mason K. $\overrightarrow{\vec{A}}$ Individual Susceptibility to Noise. In: Hamernick RP, Henderson D, Salvi R, eds. New Perspectives in Noise N Induced Hearing Loss. New York: Raven Press, 1982; $\infty$ 511-519.

18. Barone-JA, Peters JM, Garbrant DH, Bernstein KREBSBACH R. Smoking as a Risk Factor in Nois黑 $c$ Induced Hearing Loss. J Occup Med 1987; 29(9): $74 \frac{\overrightarrow{0}}{\overrightarrow{0}}$. 745.

19. SMith CR, SeITz MR, Borton TE. Modelling HTL of Industrial Workers Using Multiple Regressions ang Path Analytic Techniques. J Aud Res 1984; 24: 99-122

20. Henselman LW, Henderson D, Shadoan Subramantam M, SAunders S, OHLIN D. Effects of o Noise Exposure, Race and Years of Service on Hearing $\stackrel{2}{2}$ in U.S. Army Soldiers. Ear Hear 1995; 16(4): 382-91.

21. Pearson JD, Morrell CH, Gordon-Salant S, et-al. $\overline{\bar{o}}$ Gender Differences in a Longitudinal Study of Ageassociated Hearing Loss. J Acoust Soc Am 1995; 97(2): 1196-205.

22. SOKAS RK, MousSA MA, Gomes J, et al Noise Induced Hearing Loss, Nationality, and Blood Pressure. Am Indust Med 1995; 28(2): 281-8.

23. Fuortes LJ, TANG S, Pomrehn P, Anderson C. Prospective evaluation of associations between hearing sensitivity and selected cardiovascular risk factors. Am J Indust Med 1995; 28(2): 275-80.

24. Henderson D, Subramaniam M, Boettcher FA. Individual susceptibility to noise-induced hearing loss: an old topic revisited. Ear Hear 1993; 14(3): 152-68.

25. BoETtChER FA, HENDERSON D, GRATTON MA, DANIELSON RW, BYRNE CD. Synergistic Interactions of $\frac{D}{0}$ Noise and Other Ototraumatic Agents. Ear Hear 1987;8: 192-212.

26. FeCHTER LD. Combined Effect of Noise and $N$ Chemicals. Occup Med 1995; 10(3): 609-621.

27. JOHNSON AC, NYLÉN PR. Effects of Industrial Solvents on Hearing. Occup Med 1995; 10(3): 623-640. 
28. Morata TC, DunN DE, Kretschmer LK. Occupational Exposure to Organic Solvents and Noise: Effects on Hearing. Scand $J$ Work Environ Health 1993; 19: 245-254.

29. PekKarinen J. Noise, Impulse Noise and Other Physical Factors: Combined effects on Hearing. Occup Med 1995; 10(3): 545-559.

30. Casali JG, PARK MY. Attenuation Performance of Four Hearing Protectors Under Dynamic Movement and Different User Fitting Conditions. Hum Factors 1990; 32: 9-25.

31. POWELL RF, FORREST MR. Noise in the Military Environment. London: Brassey's, 1988: 53-64.

32. FREELAND WA. Occupational Medicine in the Army. Farnborough: Defence Research agency, 1994: 40-47.

33. OSGUTHORPE JD, KLEIN AJ. Occupational Hearing Conservation. Otolaryngol Clin North Am 1991; 24(2): 403-414.

34. Chung DY, Gannon RP, Willson GN, Mason K. Shooting, Sensorineural Hearing Loss, and Workers' Compensation. J Occup Med 1981; 23(7): 481-484.

35. Pekkarinen J, IkI M, Starck J, PyykKö I. Hearing Loss Risk from Exposure to Shooting Impulses in
Workers Exposed to Occupational Noise. Br J Audiol 1993; 27(3): 175-82.

36. Stuart A, Phillips DP, Green WB. Word Recognition Performance in Continuous and Interrupted BroadBand Noise by Normal-Hearing and Simulated Hearing-Impaired Listeners. Am J Otol 1995; 16(5): 658-63.

37. NeEdLEMAN AR, CRANDEll CC. Speech recognition in noise by hearing-impaired and noise-masked normalhearing listeners. J Am Acad Audiol 1995; 6(6): 41424.

38. Garinther GR, Peters LJ. Impact of Communications on Armoured Performance. Army $R D$ \& A 1990; Jan-Feb: 1-5.

39. Price CR, Kalb JT, Garinther GR. Towards a Measure of Auditory Handicap in the Army. Ann Otol Rhinol Laryngol 1989; 98: 42-52.

40. WRIGHT FB, Powell JA. The IRS Guide to the Noise at Work Regulations. London: Industrial Relations Services, 1993: 46-7.

41. King PF, Coles RRA, Lutman ME, Robinson DW. Assessment of Hearing Disability. London: Whurr, 1992: 47-50.

(⿸丆口

